\title{
Norwegian stress and quantity: The implications of loanwords
}

\author{
Curt Rice \\ University of Troms $\varnothing$
}

June 6, 2005

\begin{abstract}
Disyllabic Norwegian words characteristically have an initial syllable which is stressed and heavy and a final syllable which is unstressed and light. Adopting a moraic theory of syllabic representation, the weight of the initial syllable can be realized either with a bimoraic vowel or with a monomoraic vowel followed by a moraic consonant. Monosyllabic words also show variation in the length of the vowel and the coda consonant. The native data are supplemented with loanword data, leading to the claim that the grammar of Norwegian must account for patterns with stress on the ultima, the penult or the antepenult.

Stress can be assigned to both the core disyllabic and monosyllabic patterns by constructing a trochee; these patterns are equally well predicted by constructing such a foot at either the right or left edge of the word, and indeed both analyses have been advocated. The stress patterns of loanwords, however, reveal additional details about the assignment of stress, and sort out some unresolvable ambiguities arising when just considering the native vocabulary. These facts form the basis for advocating a right-edge oriented analysis of stress in Norwegian.

The solution developed here avoids diacritics for signaling the location of stress, but appeals instead to moraic specification, which is independently necessary to characterize the length constrasts in the consonants.
\end{abstract}

Keywords: Norwegian, Loanword phonology, Optimality theory, stress, syllable structure

\section{Introduction}

Stress and quantity are closely related in Norwegian (Eliasson, 1985; Fretheim, 1969; Kristoffersen, 1991, 1992, 1999, 2000, 2001, 2003; Lorentz, 1996; Riad, 1992; Rice, 1999, 2003). For the present discussion of these facts, a moraic theory of the syllable is assumed (Hyman, 1985; McCarthy and Prince, 1986; Hayes, 1989; Morén, 1999). With 
this model, the relationship can be characterized as a two-way implication holding between weight and stress: heavy syllables must be stressed and stressed syllables must be heavy; light syllables must be unstressed and unstressed syllables must be light. Since two-way implications are more straightforwardly modelled in parallel theories than in derivational ones, we adopt Optimality Theory as the framework in which we develop an analysis of the issues presented below (Prince and Smolensky, 1993; McCarthy and Prince, 1993). ${ }^{1}$

We begin in $\S 2$ with a presentation of the core facts of Norwegian, including a discussion of both disyllabic ( $\$ 2.1)$ and monosyllabic ( $(2.2)$ words. This is followed by a presentation of loanword data, in which patterns and structures not seen in the native data are present $(\S 2.3)$. In $\S 3$, we introduce the necessary constraints and their rankings. After establishing the rankings, the analysis is presented through several tableaux. Some implications and predictions of the analysis are then drawn out and shown to be validated by additional loanword data.

The core observations motivating this discussion include the following. Loanwords display patterns not seen in the native vocabulary. The presence of loanwords in the Norwegian lexicon creates a situation where stress can appear not only on the penultimate syllable, but also on either the antepenultimate or final syllables. A grammar must be constructed which returns as optimal candidates covering this range of variation. The analytical challenge is therefore to construct such a grammar and achieve these results while heeding the core methodological requirements of optimality theory, such as the hypothesis of the richness of the base, which requires that any input be mapped onto a well-formed output.

\section{Stress patterns}

\subsection{Native disyllabic words}

The prototypical disyllabic word in Norwegian has stress on its initial syllable. This syllable realizes one of two strategies for being heavy. Either it has a long vowel, or it is closed. In the latter case, the coda consonant can either be part of a geminate consonant also functioning as an onset to the second syllable, or it can be the first consonant in a consonant cluster, where the second consonant is the onset to the next

\footnotetext{
${ }^{1}$ I have worked on issues related to stress and quantity in Norwegian for several years and a comprehensive list of those who have discussed these issues with me is probably impossible at this point. Nonetheless, I would like to thank the participants at the 12th Manchester Phonology Meeting for discussion, and colleagues at my home institution for helpful input, especially Sylvia Blaho, Patrik Bye, Martin Krämer, Ove Lorentz, Bruce Morén and Tore Nesset. I would also like to thank Gjert Kristoffersen and Tomas Riad, both of whom have offered much helpful advice and feedback along the way. For written feedback on the present version of the paper, I am grateful to Michael Kenstowicz, John McCarthy, Bruce Morén, Christian Uffmann, Jeroen van de Weijer (and the Phonology Reading Group in Leiden), and Wim Zonneveld. I also thank two anonymous reviewers who gave considered and thoughtful suggestions leading to major improvements in the paper, both with respect to structure and argumentation. Responsiblity for errors of fact and analysis of course remains mine.
} 
syllable. The second syllable in these words consists of an onset and a schwa, and is unstressed.

Long vowels in the initial syllable are incompatible with coda consonants. That is, an initial syllable with a bimoraic vowel tolerates no coda consonants, while an initial syllable with a monomoraic vowel tolerates maximally one coda consonant. ${ }^{2}$ To capture this generalization with a moraic representation of the syllable, the initial syllable in a disyllabic word is bimoraic and cannot tolerate non-moraic consonants, nor can it tolerate morae which are doubly linked.

The result of the requirements and restrictions on the initial syllable is an abundance of pairs in which the stressed syllables differ only in their realization of quantity. Pairs illustrating a variety of vowel and consonant combinations are given in (1). The vowels in the column on the left are long, while those in the column on the right are short.

$$
\text { Complementary distribution of } V \text { - } \& \text { C-length in disyllabic words }
$$

$\begin{array}{llll}\begin{array}{l}\text { tape } \\ \text { ripe }\end{array} & \text { 'to lose' } & \begin{array}{l}\text { tappe } \\ \text { rippe (opp) }\end{array} & \text { 'to tap' } \\ \text { stripe } & \text { 'stripe' } & \text { strippe } & \text { 'to strip' } \\ \text { mate } & \text { 'to feed' } & \text { matte } & \text { 'mat' } \\ \text { hete } & \text { 'heat' } & \text { hette } & \text { 'hood' } \\ \text { føde } & \text { 'to give birth' } & \text { fødde } & \text { 'to feed, pret.' } \\ \text { glede } & \text { 'to make glad' } & \text { gledde } & \text { 'to make glad, pret.' } \\ \text { lade } & \text { 'to load' } & \text { ladde } & \text { 'to fill, pret.' } \\ \text { bane } & \text { 'field, lane' } & \text { banne } & \text { 'to swear' } \\ \text { rene } & \text { 'clean' } & \text { renne } & \text { 'gutter' } \\ \text { mine } & \text { 'mine' } & \text { minne } & \text { 'to remind' } \\ \text { bule } & \text { 'bump, swelling' } & \text { bulle } & \text { '(papal) bull' } \\ \text { pile } & \text { 'to move quickly' } & \text { pille } & \text { 'to finger' } \\ \text { hele } & \text { 'to heal' } & \text { helle } & \text { 'to slant' } \\ \text { mure } & \text { 'to make a wall' } & \text { murre } & \text { 'ache' } \\ \text { hake } & \text { 'chin' } & \text { hakke } & \text { 'pick' } \\ \text { rake } & \text { 'rake' } & \text { rakke } & \text { 'dog' } \\ \text { reke } & \text { 'shrimp' } & \text { rekke } & \text { 'line' } \\ \text { breke } & \text { 'bleat' } & \text { brekke } & \text { 'big hill' } \\ \text { bleke } & \text { 'to bleach' } & \text { blekke } & \text { 'newspaper (slang)' } \\ \text { kube } & \text { 'cube' } & \text { kubbe } & \text { 'log' }\end{array}$

\footnotetext{
${ }^{2}$ I am aware of two possible exceptions to this generalization, the first of which is the Norwegian pronunciation of the place name Bethlehem, which is pronounced with a long vowel in the stressed initial syllable. This leaves us in the situation of either syllabifying [tl] as the onset to the second syllable, as proposed by Kristoffersen (2000) or tolerating a non-word final syllable with both a long vowel and a coda consonant, as discussed by Rice (2001). Ove Lorentz (p.c.) has recently suggested that the explanation for this pronunciation may lie in its pronunciation in a popular Christmas song. The second exception is arktis 'arctic' which looks like a short vowel followed by the cluster [rk], since $[\mathrm{kt}]$ is not a possible onset cluster.
} 


$\begin{array}{llll}\text { same } & \text { 'a Saami person' } & \text { samme } & \text { 'same' } \\ \text { grime } & \text { 'harness' } & \text { grimme } & \text { 'ugly, pl.' } \\ \text { klase } & \text { 'bunch of fruit or flowers' } & \text { klasse } & \text { 'class' } \\ \text { buse } & \text { 'to barge in' } & \text { busse } & \text { 'kind of ship' } \\ \text { lise } & \text { 'pain relief' } & \text { lisse } & \text { 'shoe lace' } \\ \text { suge } & \text { 'to suck' } & \text { sugge } & \text { 'sow' } \\ \text { ruge } & \text { 'to brood' } & \text { rugge } & \text { 'to rock' }\end{array}$

The core properties of an analysis of these data will place primary stress on the initial syllable and insure that this syllable is heavy at the same time as the second, unstressed syllable must be light. One strategy for achieving this result requires that stress be aligned with the left edge of the word and that stressed syllables be heavy. An equally successful strategy would require that stress be aligned with the right edge of the word, as long as the constraint achieving this is dominated by a constraint prohibiting final stress. The first of these two competing grammars would place stress on the initial syllable while the second places stress on the penultimate syllable. Obviously, the results are the same in the case of disyllabic words and the analyses can therefore only be distinguished by examining longer words, cf. Rice (1999). In the longer words discussed there, most of which have been borrowed into the language, e.g. bikini, stress is on the penult. This is not compatible with an analysis aligning stress with the left edge and we therefore adopt the right-edge based analysis.

Regarding the specific properties of the stress foot, there are two possibilities. One would show a moraic trochee dominating exactly the initial syllable, which has in its bimoraicity the properties necessary for supporting such a foot. An alternative construction would have an uneven trochee with the initial heavy syllable as its head and the final light one as its non-head. The metrical theory advocated by Hayes (1995) precludes the possibility of an uneven HL trochee, although this option has been defended in the context of parametric approaches to foot typology, cf. Rice (1992). The moraic trochee is employed here to emphasize the parallels between the metrical structure of the disyllabic words and the monosyllabic ones. Given the moraic trochee, the final syllable of the disyllabic words will be left unfooted.

To highlight a basic difference between an optimality theoretical analysis of Norwegian stress and quantity and a derivation approach, I note here that the analysis proposed below will not use the (head of the) stress foot as a strategy for identifying a syllable to be lengthened nor will it use syllable quantity as a strategy for identifying syllables which must be the head of a foot. In a fashion typical of parallel analyses, the optimality theoretical analysis below assumes neither that weight precedes stress foot construction, nor the converse. In this way, the OT approach need not take a position regarding which of these mutually dependent properties should be considered basic and which should be derived, cf. Kristoffersen (1991, 2000). 


\subsection{Monosyllabic words}

Norwegian is also rife with monosyllabic words. There are three possible shapes for such words. They can be open syllables with a long vowel, as in $f e$ 'fairy', le 'shelter', bi 'bee', $h i$ 'lair', etc. Monosyllabic words may also consist of a single closed syllable. Just as we saw with the stressed syllables in the disyllabic words in (1), these monosyllabic words show complementary distribution of vowel and consonant length. They either have a long vowel followed by a short consonant, or they have a short vowel followed by a long consonant or a consonant cluster. The claim that the vowels in these pairs of monosyllabic words vary in length is uncontroversial. In addition to being particularly salient impressionistically, research has shown that it is precisely the variation in vowel length which cues speaker judgments for word identification (Behne, Czigler, and Sullivan, 1998b). Speakers are less attuned to contrasts in consonant length in word-final position. Nonetheless, the length difference is reliably present (Behne, Czigler, and Sullivan, 1998a).

In the orthographic representations given in (2), a vowel followed by a single consonants indicates a long vowel with a short consonant, while a vowel followed by an orthographic geminate indicates a short vowel followed by a long consonant.

\begin{tabular}{|c|c|c|c|}
\hline hat & 'hatred' & hatt & 'hat' \\
\hline tak & 'ceiling' & takk & 'thanks' \\
\hline rap & 'burp' & $\operatorname{rapp}$ & 'kind of grass' \\
\hline råd & 'advice' & rådd & 'advise, part.' \\
\hline vis & 'manner' & viss & 'certain' \\
\hline $\operatorname{vad}$ & 'ford (in a river)' & vadd & 'to wade, part.' \\
\hline stek & 'steak' & stekk & 'to clip wings, imp.' \\
\hline skjøt & 'joint' & skjøtt & 'to splice, pret.' \\
\hline pur & 'pure' & purr & 'to remind, imp.' \\
\hline lut & 'lut' & lutt & 'lute' \\
\hline$e g$ & 'I' & egg & 'egg' \\
\hline ren & 'clean' & renn & 'ski competition' \\
\hline stab & 'staff' & stabb & 'to walk heavily, imp.' \\
\hline steg & 'step' & stegg & 'male quail' \\
\hline
\end{tabular}

Here again, an adequate analysis must put stress on the initial syllable, presumably a trivial task for monosyllabic words. The analysis must also insure that a vowel followed only by a singleton consonant is long.

\subsection{Stress patterns in loanwords}

The picture of Norwegian presented above is incomplete for the contemporary language. In this section, a richer set of data are presented. We refer to the data presented here as 
loanwords, and this is indeed confirmed in Landrø and Wangensteen (1986). However, while some of the loans are fairly recent, many are not. We take the fact that many of these words have been in the language for generations as support for the general enterprise of identifying a single grammar which accounts not only for the native data in $\S 2.1$ and $\S 2.2$, but also for the loan data given here. Our approach asserts that a speaker natively acquiring Norwegian encounters no evidence for approaching grammar construction with the aid of co-phonologies or diacritics or different strata. The null hypothesis is that there is one grammar returning all of the patterns.

The loanword data preserve the core requirement that the stressed syllable be bimoraic. However, the loanwords show more stress patterns than do the native ones. One striking point of variance is found in loans with stress on final open vowels. Words which are borrowed with stress on final open syllables are found in Norwegian with their stress preserved in the source language position. Relevant data include those in (3) (given accents are in the orthography). Glosses are not given since they are identical with the Norwegian forms, except for slight differences in some orthographic conventions.

Final open syllables with final stress:

orkidé, obo, agora, akribi, allé, armé, buffet, debut, depot, diskret, filet, gelé, geni, ironi, kafé, kopi, kupé, meny, nivå

Two remaining sets of data are presented, all of which reveal that disyllabic loanwords can have final closed syllables in contrast with the data in (1). These words can have either final or penultimate stress.

The data in (4) have final syllables closed by either one or more consonants. (The accents indicate stress and are not in the orthography. Glosses are included only when not essentially identical.)

Final consonants with penultimate stress:

álbum, átlas, bálsam, bámbus ('bamboo'), básis ('foundation'), bíson, bónus, dóktor, éddik ('vinegar'), fáktor, fénrik ('second-lieutenant'), fókus, grátis ('free') hállik ('pimp'), húmor, kétsjup, kóbolt, kókos ('coconut') kónsul, krókus, sénnep ('mustard') klímaks, bóraks, lárynks, ádvent, ápeks, appéndiks, ásfalt, bíceps, bóraks, fárynks, Fóniks, hárpiks, háubits, kóbolt

There are also disyllabic words ending in consonants which have stress on the final syllable, as in(5). These may also end in a single consonant or a cluster or geminate. If the words end orthographically in two consonants (either a geminate or a cluster), the vowel in the final syllable is short. If they end orthographically in one consonant, then the vowel of the final syllable is long.

(5) Final consonants with final stress:

agúrk ('cucumber'), fagótt ('bassoon'), hospíts ('hospice'), kondóm, korréks ('correction'), natúr, París, parýkk ('wig'), tomát, trafikk 
We have seen now that the loanwords can deviate from the native vocabulary with respect to the placement of stress. Vowel-final loans can have final stress, as in (3). Loanwords can also end in consonants, unlike the prototypical native words in (1). Such nouns can have either penultimate or final stress, independent of whether they end in a single consonant or a cluster. With the data now on the table, we turn to a presentation and ranking of the relevant constraints.

\section{Constraints and rankings}

The data seen in $\S 2$ can be analyzed with constraints well establish in the OT literature. In the present section, the relevant constraints are presented and arguments for various subrankings are made.

One of the strongest generalizations about the disyllabic data in (1) is that stress is not placed on the final syllable of the word. Although the data in $\S 2.3$ show that this generalization is not surface true in the language, we will see below that NonFinALITy can assert itself under certain circumstances. Prince and Smolensky (1993: 42) formalize this constraint as in (6).

(6) Nonfinality: The prosodic head of the word does not fall on the word-final syllable.

The prosodic head is the syllable bearing main stress and the constraint NonFinALITY is therefore understood to mean that a word-final syllable does not bear main stress.

The location of stress in the disyllabic data presented in (1) can be predicted by a grammar with NonFinAlity as a highly ranked constraint. However, the location of stress in longer words cannot be determined by this constraint alone. Although such words will not be of central concern here, we follow Rice (1999) in claiming that the alignment constraint in (7) places stress as far to the right as possible, while NonFINALITY keeps it off a word-final syllable.

Align(HPrWd, R, PrWd,R): For every head of a prosodic word (syllable bearing main stress), there is a prosodic word such that the right edge of the head of the prosodic word coincides with the right edge of the prosodic word (Prince and Smolensky, 1993).

NonFinality must dominate AlignRight in the grammar of Norwegian. This is clear from the simple tableau in (8) which shows the classical ranking argument, whereby candidate (a) satisfies the most highly ranked constraint while it violates the lower constraint, and candidate (b) violates the most highly ranked constraint and satisfies the lower ranked constraint. Given that candidate (a) represents the form actually found in the data, it is clear that the ranking must be that seen here. (This simple tableau leaves aside the representation of quantity and footing, both of which will be presented in greater detail below.) 


\begin{tabular}{|rl||c|c|}
\hline & hake & NonFinality & AlignRight \\
\hline \hline a. & há.ke & & $*$ \\
\hline b. & ha.ké & $* !$ & \\
\hline
\end{tabular}

In addition to the correct placement of stress, the grammar of Norwegian must also return the correct distribution of quantity. As noted above, there is a two-way implication between stress and quantity, such that bimoraic syllables must be stressed, and stressed syllables must be bimoraic. These relations are captured with the constraints (9) and (10) (Prince, 1990). We will see below that there may be circumstances under which Weight-To-Stress can be violated, while Stress-To-Weight is unviolated on the surface and therefore placed at the top of the constraint hierarchy.

(9) Stress-to-Weight: A stressed syllable must not be monomoraic.

(10) Weight-to-Stress: A bimoraic syllable must bear stress.

Also important to the correct distribution of quantity is the familiar constraint FooTBinARITY, which requires that feet be binary at the level of the syllable or the mora. Candidates with a monosyllabic, trimoraic foot will be punished by this constraint.

(11) FootBinarity: A foot is binary at the level of the syllable or the mora (Prince and Smolensky, 1993).

FootBinARITy is also unviolated on the surface, and therefore ranked in the same position as (9). Our tableaux will show these two constraints as being unranked with respect to one another by separating them with dashed lines, following OT conventions.

The final two constraints included in this analysis address the status of moraic coda consonants. With NoCoDA included by hypothesis as part of the universal inventory of constraints, the fact that Norwegian can have stressed syllables with coda consonants must be the result of a competing constraint rewarding the presence of some codas.

In our analysis, an output in which the stressed syllable has a coda will be optimal when the consonant is moraic in the input (unless the vowel in the input is bimoraic, as we will see below). In other words, the effects of NoCODA are overridden by a faithfulness constraint which will punish a correspondence relation in which the input member of the pair is moraic while the output member is not. This will be a MAX constraint, and to emphasize that the reassociation of morae is not to go unpunished (lest all stressed syllables be open with long vowels), we employ one of Morén's (1999) MAXLinK constraints.

(12) NoCodA: A syllable does not have a coda (Prince and Smolensky, 1993: 93) .

(13) MAxLink- $(\mu)[\mathrm{SEG}]$ : For two corresponding segments, if $\mathrm{S}_{1}$ (in the input) is associated to a mora, then $\mathrm{S}_{2}$ (in the output) is associated to a mora (Morén, 
1999).

MAXLink must dominate NoCODA to allow an input with a moraic consonant to surface with a coda. A simple tableau illustrating this ranking is given in (14).

Tableau illustrating MAxLINK- $(\mu)[\mathrm{SEG}] \gg$ NoCODA

\begin{tabular}{|rl||c|c|}
\hline & ha $_{\mu} \mathrm{k}_{\mu} \mathrm{e}_{\mu}$ & MAXLINK- $(\mu)[\mathrm{SEG}]$ & NoCoda \\
\hline \hline a. & $\left(\right.$ há $\left._{\mu} \mathrm{k}_{\mu} \cdot\right) \mathrm{ke}_{\mu}$ & & $*$ \\
\hline b. & $\left(\right.$ há $\left._{\mu \mu}.\right) \mathrm{ke}_{\mu}$ & $* !$ & \\
\hline
\end{tabular}

The ranking demonstrated here has the effect of preserving a moraic consonant as moraic, even at the cost of having a coda. The input in this tableau has a moraic consonant, a situation which is preserved only in candidate (a). This consonant is doubly linked, being syllabified both as an onset to the second syllable and as a coda in the first syllable, yielding a violation of NoCODA. Were the ranking of these two constraints reversed, the syllabification of the consonant as a coda would always disqualify such a candidate from being optimal, since there would be a competitor like candidate (b), in which the consonant is no longer associated with the mora to which it was linked in the input. Candidate (b) is otherwise well-formed, since its initial syllable is stressed and heavy, as represented with the bimoraic vowel in that syllable.

While we have seen that MAXLink must dominate NoCODA to preserve the link between an input consonant and a mora, there will nonetheless be situations in which MAXLink will be violated. For example, FootBinARITY can compel a violation of MAXLink. This can be seen in tableaux with an input showing a bimoraic vowel followed by a moraic consonant. FootBINARITY will require that one of the three morae not be present in the output. While it is logically possible that any of the three could be absent in the output, the effects of low-ranked NoCoDA will always prefer a candidate in which the mora has been removed from the consonant rather than the vowel, in a typical emergence of the unmarked effect (McCarthy and Prince, 1994). Again, many relevant candidates and constraints are set aside in the following simplified tableau, which merely illustrates the flavor of the ranking argument given here.

Tableau illustrating FootBinarity $\gg \operatorname{MAxLinK-}(\mu)[\mathrm{SEG}]$

\begin{tabular}{|rl||c|c|c|}
\hline & ha $_{\mu \mu} \mathrm{k}_{\mu} \mathrm{e}_{\mu}$ & FootBin & MAXLink- $(\mu)$ & NoCODA \\
\hline \hline a. $\left(\mathrm{há}_{\mu \mu} \mathrm{k}_{\mu}\right) \cdot \mathrm{ke}_{\mu}$ & $* !$ & & \\
\hline b. $\left(\mathrm{há}_{\mu \mu}\right) \mathrm{ke}_{\mu}$ & & $*$ & \\
\hline c. $\left(\mathrm{há}_{\mu} \mathrm{k}_{\mu}\right) \cdot \mathrm{ke}_{\mu}$ & & $*$ & $* !$ \\
\hline
\end{tabular}

We must also explore the ranking of MAxLink- $(\mu)[\mathrm{SEG}]$ and NonFinality. These constraints will come into conflict when an input has a bimoraic final syllable. In that 
case, if the syllable remains bimoraic in the output, the undominated WEIGHT-TOSTRESS will compel it to be stressed. This of course is in violation of NonFinality. To respect NonFinality, the final syllable must remain unstressed, which requires losing a mora. The loss of a mora leads to a violation of MAXLinK- $(\mu)[\mathrm{SEG}]$. Hence, the optimal output associated with an input having a bimoraic final syllable cannot satisfy both of these constraints.

It is furthermore the case that NONFINALITY will operate to block final stress in all other cases. That is, if no faithfulness constraint is relevant, a candidate output with final stress will never be optimal. Hence, an instance of final stress implies an input with a bimoraic final syllable. The claim that MAxLinK- $(\mu)[\mathrm{SEG}]$ dominates NonFinALiTy is thereby motivated through the identification of words with final stress, e.g. those in (3). The success of this ranking is illustrated in (16).

Tableau for orkidé, with MAxLink, Weight-TO-Stress $\gg$ NonFinality

\begin{tabular}{|c|c|c|c|c|}
\hline & $\mathrm{o}_{\mu} \mathrm{rki}_{\mu} \mathrm{de}_{\mu \mu}$ & $\operatorname{MAxLINK}-(\mu)_{\mu}$ & WS & $\mathrm{NF}$ \\
\hline & "a. $\quad \mathrm{o}_{\mu} \mathrm{r}\left(\mathrm{kí}_{\mu \mu}\right) \mathrm{de}_{\mu}$ & "*! & & \\
\hline & b. $\quad \mathrm{o}_{\mu} \mathrm{r}\left(\mathrm{ki}_{\mu \mu}\right) \mathrm{de}_{\mu \mu}$ & & $* !$ & \\
\hline$\left[\begin{array}{cc}8 \\
8\end{array}\right.$ & c. $\mathrm{o}_{\mu} \mathrm{rki}_{\mu}\left(\right.$ dé $\left._{\mu \mu}\right)$ & & & * \\
\hline
\end{tabular}

Candidate (a) respects NonFinality and achieves conformity with WEIGHT-TOSTRESS by deleting one of the final morae, offering an output with penultimate stress. The cost of this conformity, however, is a fatal violation of MAXLinK- $(\mu)$ [SEG]. Candidate (b) in (16) preserves the morae found on the word-final vowel of the input, respecting MAXLinK- $(\mu)[\mathrm{SEG}]$. It also has stress on the penultimate syllable, respecting NonFinality. This candidate nonetheless is suboptimal because of its violation of Weight-To-Stress. Candidate (c) with its final stress avoids deleting any morae and stresses the bimoraic syllable. This can be achieved only by stressing the word final syllable, and incurring a violation of NonFinAliTy. This is in fact the surface pattern, confirming the proposed ranking of MAXLink- $(\mu)$ [SEG] over NonFinALiTy.

The ranking we have motivated in (16) may be surprising in light of the stress patterns seen in the native data. An analysis which fails to account for the loanword data would in fact rank NonFinality above MAxLink- $(\mu)[\mathrm{SEG}]$. Such a ranking respects the principle of the richness of the base (Prince and Smolensky, 1993: 209) by taking even unattested inputs, such as those with final stress, and mapping them onto outputs with penultimate stress, as in Rice (2003). This would be a mistake. The driving force behind the present analysis is that the (sometimes historical) loanwords introduce patterns which now must be considered part of the repertoire the grammar must return. While there may be relatively few such words in Norwegian, their number is surely not as important as their status.

Seven well-motivated constraints are invoked for the analysis of stress and quantity in Norwegian. Five crucial subrankings have been identified to this point, and a sixth will become relevant in $\S 5.3$ below. The rankings are summarized in (17). 
Summary of crucial constraint rankings

a. FootBinarity $\gg$ MaxLink- $(\mu)[\mathrm{SEG}],(15)$

b. MaXLinK- $(\mu)[\mathrm{SeG}] \gg$ Weight-TO-STRESS, $\S 5.3$

c. MaxLink- $(\mu)[\mathrm{SEG}] \gg$ NonFinality, $(16)$

d. Weight-TO-Stress $\gg$ NonFinality, (16)

e. MaxLink- $(\mu)[\mathrm{SEG}] \gg$ NoCoda, $(14)$

f. NonFinality $\gg$ AlignRight, (8)

When we combine these rankings with the claim that StREss-TO-WeIGHT and FootBINARITY are undominated, we can then determine an overall ranking of the constraints, representing both crucial and noncrucial rankings.

\section{Overall constraint ranking, including noncrucial rankings}

$\mathrm{SW}, \mathrm{FB} \gg \operatorname{MaxLink}-(\mu)[\mathrm{SEG}] \gg \mathrm{WS} \gg \mathrm{NF}, \mathrm{NoCodA} \gg$ AlignRight

Note that NoCoda is not in a crucial relationship to either NonFinality or AligNRIGHT and therefore could be at the same level as either of those two constraints. The only crucial ranking involving NoCoDA is the one which puts it below MAxLink$(\mu)[\mathrm{SEG}]$.

We turn now to a demonstration that this ranking returns all of the patterns seen in Norwegian.

\section{Analysis and tableaux}

An analysis of stress and quantity in Norwegian is to be evaluated on its success in identifying the set of possible constructions, and its concomitant success in keeping forms which are ungrammatical in the language from being returned as optimal in any tableau. This section presents several tableaux which illustrate the success of the grammar proposed in (18).

First, we illustrate the grammar's evaluation of disyllabic native forms, followed by its evaulation of monosyllabic forms. We then turn to the loan patterns.

\subsection{Disyllabic native words}

All of the tableaux illustrating the disyllables have exactly the same set of candidate outputs. Furthermore, six of the seven constraints are markedness constraints; this means that the variation in the inputs is irrelevant to the evaluation of these constraints with the result that the violations are identical in all tableaux for all of the markedness constraints. The tableaux therefore vary in exactly two ways: the inputs are different, and the violations of the faithfulness constraint MAxLinK- $(\mu)[\mathrm{SEG}]$ are different.

Example (19) gives a tableau in which the input is disyllabic and has a final open syllable. In this particular case, the input shows no prosodification, neither foot struc- 
ture nor syllable structure. Each of the vowels is associated with one mora in the input, while the intervocalic consonant is not. The grammar maps this input onto a disyllabic form with stress on the initial syllable, where the vowel in that syllable has been augmented.

$$
\text { Optimizing } C \hat{V}_{\mu \mu} . C V_{\mu}
$$

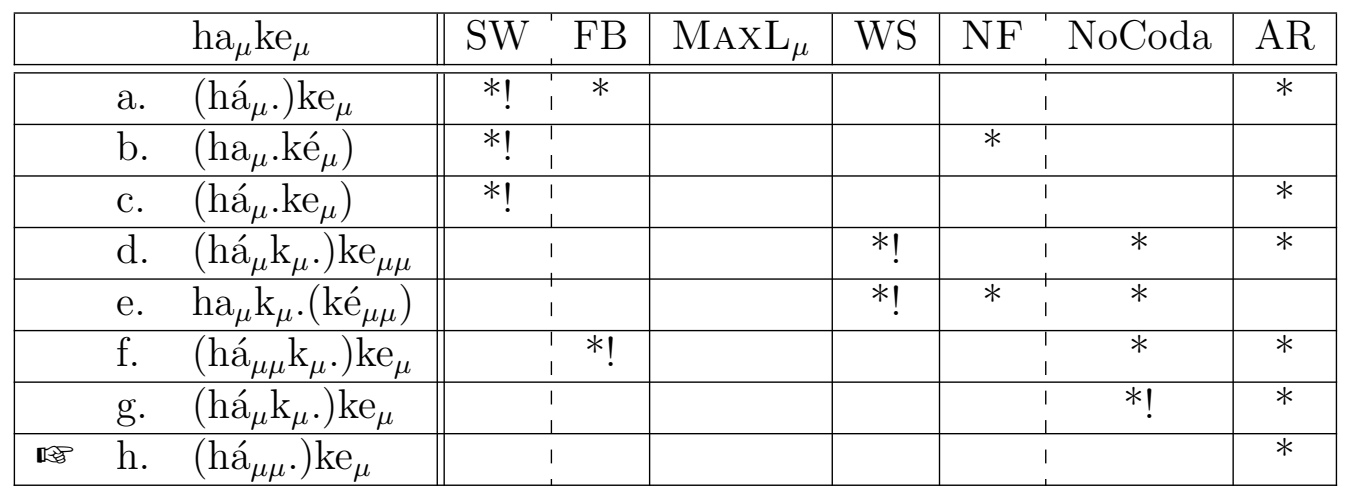

Stress-To-Weight requires that stressed syllables be heavy. Since the stressed syllables in candidates (a-c) are not heavy, they violate this constraint. Candidates (d) and (e) have unstressed heavy syllables, thereby fatally violating WEIGHT-TO-STRESS. If there is a monomoraic or trimoraic foot - as in candidates (a) and (f) - the candidate violates FootBinARITY; this violation is fatal for candidate (f).$^{3}$

Candidates $(\mathrm{g})$ and $(\mathrm{h})$ are the only two candidates satisfying all of the highly ranked markedness constraints. Therefore, one of these two candidates will be optimal in all tableaux. Both $(\mathrm{g})$ and $(\mathrm{h})$ satisfy the faithfulness constraint MAxLinK- $(\mu)[\mathrm{SEG}]$, and they both violate the low-ranked AlignRight. The only constraint distinguishing these two candidates is NoCODA, which is violated by candidate $(\mathrm{g})$ while it is satisfied by candidate $(\mathrm{h})$. Candidate $(\mathrm{h})$ is therefore selected as optimal. Note that intervocalic geminates are represented as $\left[\mathrm{C}_{\mu} . \mathrm{C}\right]$ in the candidate outputs, which is intended to correspond to the notion of a doubly-linked consonant, forming both a moraic coda for the first syllable and an onset for the second. The onset for the second syllable will be preferred by the familiar constraint ONSET; this constraint and candidates which would be ruled out by it are left aside below.

The next tableau to consider has an input in which the intervocalic consonant is linked to a mora. As we see in (20), the grammar proposed in (18) returns as optimal candidate $(\mathrm{g})$, with an intervocalic geminate. Candidate $(\mathrm{h})$ violates the faithfulness constraint because the mora on the consonant in the input has been lost in the output. Note that a simply $\operatorname{MAx}(\mu)$ would not be violated by candidate $(\mathrm{h})$, since the three moras in the input might be said to all be present in the output. Reference to the

\footnotetext{
${ }^{3}$ Since Stress-To-Weight and FootBinarity are unranked with respect to one another, there is no clear notion by which one violation or the other for candidate (a) can be said to be fatal. We mark the leftmost violation as fatal here simply to facilitate the reader's processing of the tableau.
} 
linkage between mora and segment is crucial for this analysis.

$$
\text { Optimizing } C \dot{V}_{\mu} C_{\mu} . C V_{\mu}
$$

\begin{tabular}{|c|c|c|c|c|c|c|c|c|}
\hline & $\mathrm{ha}_{\mu} \mathrm{k}_{\mu} \mathrm{e}_{\mu}$ & SW & $\mathrm{FB}$ & $\mathrm{MAXL}_{\mu}$ & WS & $\mathrm{NF}$ & NoCoda & $\mathrm{AR}$ \\
\hline & a. $\quad\left(\right.$ há $\left.{ }_{\mu}.\right) \mathrm{ke}_{\mu}$ & & * & ( & & & & * \\
\hline & b. $\quad\left(\right.$ ha $\left._{\mu} \cdot \mathrm{ké}_{\mu}\right)$ & $* !$ & & * & & * & & \\
\hline & c. $\left(\right.$ há $\left._{\mu} \cdot \mathrm{ke}_{\mu}\right)$ & $* !$ & & & & & & $*$ \\
\hline & d. $\quad\left(h^{\prime} \mathrm{k}_{\mu} \mathrm{k}_{\mu}\right) \mathrm{ke}_{\mu \mu}$ & & & & $* !$ & & $*$ & $*$ \\
\hline & e. $\mathrm{ha}_{\mu} \mathrm{k}_{\mu} \cdot\left(\mathrm{ké}_{\mu \mu}\right)$ & & & & $* !$ & * & $*$ & \\
\hline & f. $\quad\left(\right.$ há $\left._{\mu \mu} \mathrm{k}_{\mu} \cdot\right) \mathrm{ke}_{\mu}$ & & $* !$ & & & & * & $*$ \\
\hline & g. $\quad\left(\right.$ há $\left._{\mu} \mathrm{k}_{\mu} \cdot\right) \mathrm{ke}_{\mu}$ & & & & & & $*$ & * \\
\hline & h. $\quad\left(\right.$ há $\left._{\mu \mu}.\right) \mathrm{ke}_{\mu}$ & & & $* 1$ & & & & * \\
\hline
\end{tabular}

The violations of Stress-to-Weight, FootBinarity and Weight-to-Stress in (20) are the same as in (19). In (20), (g) and (h) are distinguished by the faithfulness constraint, since the correspondence relation between $/ \mathrm{k}_{\mu} /$ in the input and $[\mathrm{k}]$ in the output in (h) shows a relevant difference, namely the loss of the linkage to a mora. The violation of the lower ranked NoCoDA by candidate $(\mathrm{g})$ is irrelevant to the selection of the optimal candidate here, since all other candidates incur fatal violations of more highly ranked constraints.

Candidates (g) and (h) are the only two which will ever be optimal given this grammar. Because markedness constraints are evaluated independent of the input, a tableau with any configuration in the input will therefore have identical markedness violations, given that the candidate set is identical for all tableaux (which follows logically from the hypothesis of freedom of analysis, which allows Gen to freely manipulate the structure of the input (Prince and Smolensky, 1993)).

When MAxLink- $(\mu)[\mathrm{SEG}$ ] fails to distinguish $(\mathrm{g})$ and $(\mathrm{h})$ then $(\mathrm{h})$ will be optimal, since (g) will be eliminated by NoCodA. MAxLink- $(\mu)[\mathrm{SEG}$ ] will fail to distinguish (g) from (h) when both candidates satisfy MAxLink- $(\mu)[\mathrm{SEG}]$ - as in (19) - or when both candidates violate MAXLINK- $(\mu)[\mathrm{SEG}]$ — as in $(21)$.

Optimal violation of MAXLINK- $(\mu)[\mathrm{SEG}]$

\begin{tabular}{|c|c|c|c|c|c|c|c|c|}
\hline & $\mathrm{ha}_{\mu \mu} \mathrm{k}_{\mu} \mathrm{e}_{\mu}$ & SW & $\mathrm{FB}$ & $\mathrm{MAXL}_{\mu}$ & WS & NF & NoCoda & AR \\
\hline & a. $\left(\right.$ há $\left._{\mu}.\right) \mathrm{ke}_{\mu}$ & $* !$ & $*$ & $* *$ & & & & $*$ \\
\hline & b. $\left(\right.$ ha $\left._{\mu} \cdot \mathrm{ké}_{\mu}\right)$ & $* !$ & & $* *$ & & $*$ & & \\
\hline & c. $\quad\left(\right.$ há $\left._{\mu} \cdot \mathrm{ke}_{\mu}\right)$ & $* !$ & & $*$ & & & & $*$ \\
\hline & d. $\quad\left(h^{\prime} \mathrm{k}_{\mu}.\right) \mathrm{ke}_{\mu \mu}$ & & & $*$ & $* !$ & & $*$ & $*$ \\
\hline & e. ha $_{\mu} \mathrm{k}_{\mu} \cdot\left(\mathrm{ké}_{\mu \mu}\right)$ & & & $*$ & $* !$ & $*$ & $*$ & \\
\hline & f. $\quad\left(\right.$ há $\left._{\mu \mu} \mathrm{k}_{\mu} \cdot\right) \mathrm{ke}_{\mu}$ & & $* !$ & & & & $*$ & $*$ \\
\hline & g. $\quad\left(\right.$ há $\left._{\mu} \mathrm{k}_{\mu} \cdot\right) \mathrm{ke}_{\mu}$ & & 1 & $*$ & & & $* !$ & $*$ \\
\hline & h. $\quad\left(\right.$ há $\left.{ }_{\mu \mu}.\right) \mathrm{ke}_{\mu}$ & & I & $*$ & & & & $*$ \\
\hline
\end{tabular}


In (21), candidates (a-c) and candidate (f) are eliminated by the now familiar violation of markedness constraints. Note that the input has a bimoraic vowel and a moraic consonant; FоотBinARITY compels the elimination of one of these three morae, cf. candidate (f).

Candidates (d-e) and (g-h) are left undistinguished by MAxLinK- $(\mu)[\mathrm{SEG}]$, although in this case, they are undistinguished because they all violate it. Candidates (d) and (e) are eliminated by their familiar violation of WEIGHT-TO-STRESS.

Since $(\mathrm{g})$ has a coda consonant and thereby violates NoCODA, it loses out to $(\mathrm{h})$. The selection of candidate (g) as optimal in (20) therefore depends not only on the presence of a moraic consonant in the input, but also depends on the fact that the first vowel in the input is not bimoraic.

Based on the data given in (1), we know that native disyllabic words in Norwegian show little variation in their prosody. Stress is always initial, the initial syllable is always heavy, and the final syllable is always unstressed and light. The grammar developed above and illustrated through the tableaux here returns one of two candidates as optimal, corresponding to the two weight patterns in (1).

We have also seen that Norwegian can allow stress on a final open syllable, as seen in the data in (3) and the tableau in (16), where the input had a bimoraic final vowel. In sum, then, the grammar can return initial stress on a disyllabic word, giving either a long vowel or a short vowel with a coda, or it can give stress on a final vowel. These patterns are found in the language, and the correctness of the grammar is thereby affirmed through this result.

We turn now to a consideration of words ending in consonants, including both disyllabic loanwords, as in (4) and (5), and monosyllabic native words, as in (2).

\subsection{Final closed syllables}

An analysis correctly predicting the location of stress on words with final closed syllables depends nontrivially on the syllabification adopted for word-final consonants. Optimality theory, of course, is not a theory of structure and is therefore compatible with any of the myriad theories of syllable and foot structure to be found in the literature, cf. Blevins (1995) for a review of selected theories. While our purposes here do not include a thorough consideration of the typology of word-final consonants, the matter cannot be ignored. We therefore identify the crucial issues and propose a structure capturing the necessary properties.

Recall that there are strict limitations on the size of non-word-final syllables. If the vowel is long, there can be no coda consonant; if the vowel is short, there can be just one coda consonant. We suggested above that one way to formalize this situation is to require post-vocalic consonants to either be moraic or to be an onset, in the spirit of weight-by-position (Hayes, 1989). Morae must also be restricted such that they maximally dominate one segment. In this way, a bimoraic syllable will have only the two allowed shapes. Our proposal for the treatment of word-final closed syllables should not undermine this treatment of the non-word-final ones, which is assumed throughout 
even if it is left unformalized. Candidates lacking these properties are simply ignored.

At first glance, word-final closed syllables would appear to have different properties than the word-medial ones. In word-final position, it appears that a long vowel can be followed by a consonant, or that a short vowel can be followed by two. Of course, that is also true in non-final position, but the consonant following a long vowel must be an onset as must the second consonant following a short one. It would seem that there is an extra 'slot' word finally.

The literature includes several proposals regarding the possibility of extrasyllabic word-final consonants. Words may have a final appendix, cf. Selkirk (1982), or a final catalectic syllable, cf. Kiparsky (1992); Kager (1995); Burzio (1995), or a final licensed onset, cf. Kaye (1990); Scheer (2005); Harris and Gussman (2003). For our purposes here, the specific model is not particularly important. We adopt the view that word final consonants can be syllabified as onsets. Whether this is construed as an onset to an otherwise empty syllable or simply an onset constituent has no impact on the details of this analysis. However, the moraic theory of syllable structure which we adopt here has no onset constituent and we therefore assume that a word final consonant is an onset in the sense of being linked to a following catalectic syllable. By treating wordfinal consonants as onsets, we are spared discussing the details of why an appendix or non-moraic consonant is possible only in word-final position. This is represented in the tableaux below by placing the syllable boundary before the final consonant. While a catalectic syllable could be part of a foot, we consider no such candidates, given that they violate NonFinality. The foot boundary (right parenthesis) is therefore placed before the consonant.

This view of syllabification is also relevant for the treatment of final geminates in Norwegian. Recall the representation of the intervocalic geminates in disyllabic words. There, we assume that the consonant in question is doubly-linked. On the left, it is linked to a mora, which in turn is linked to a syllable, such that it serves as a coda for that syllable. On the right, it is linked to a syllable, and functions as an onset. This representation is one of the standards in moraic theory, and receives extensive motivation in McCarthy and Prince (1986). An alternate proposal which maintains a segmental perspective on geminate structures is advance by Selkirk (1990). Discussion of the relative merits of these models can be found in Broselow (1995), Ringen and Vago (2002), Davis (2003), and Curtis (2003), among others.

The importance of this strategy is clear already in the treatment of words which have both final closed syllables and penultimate stress.

\subsubsection{Penultimate stress}

Knowing the effects of the lone faithfulness constraint, as seen above, we can easily determine that penultimate stress will only be possible when the input has a single mora on its final vowel and no mora on its final consonant. (When using descriptors such as 'penultimate' and 'final' below, the catalectic syllable is not being counted.) This will be the approach for deriving the location of stress for the words in (4), such 
as eddik 'vinegar'.

Penultimate CVC stress with a final closed syllable

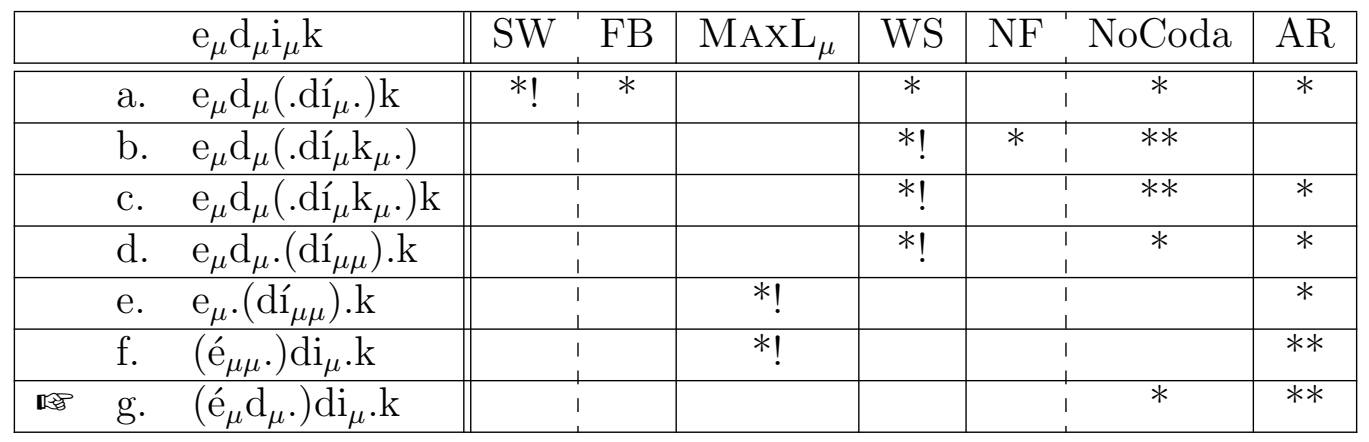

Note that there are no candidates in which a nonmoraic final consonant is included as a coda. There is, for example, no candidate $\left(\dot{e}_{\mu} \mathrm{d}_{\mu}\right.$. $) \mathrm{di}_{\mu} \mathrm{k}$. Such a candidate would violate the basic syllabification procedure outlined above, specifically by having a nonmoraic coda consonant. It would also incur an extra violation of NoCoDA and therefore lose to candidate $(\mathrm{g})$. Note also that once the door is opened to word final onsets, a final moraic consonant can be syllabified in the same was as an intervocalic one, namely as both a coda and as an onset. Gen may of course supply candidates like candidate (b) above, which has a moraic consonant that is just a coda and not an onset. This leads to a violation of NonFinality, and given that NonFinality dominates AlignRight, cf. (8), a doubly-linked final moraic consonant will give a better result than one which is just a coda.

The assessment of violations for NonFinality and AlignRight require comment in light of the syllabification adopted above. We assume here that a final onset acts as a buffer between the final 'full' syllable and the right edge of the word. Because of this, candidates (a), (c-e) do not violate NonFinALITY. The only candidates violating NonFinAliTy are those in which the right edge of the syllable bearing main stress coincides with the right edge of the word.

AlignRight is satisfied in exactly the situation where NonFinALITY is violated. The number of violations of ALIGNRIGHT is determined by counting the number of syllables between the stressed syllable and the right edge of the word. Candidate (a) gets one violation because of the final syllable (containing only the onset $[\mathrm{k}]$ ) while candidates (f-g) get two.

The other violations in (22) are familiar from the earlier tableaux. For example, in candidate (a), the stressed syllable is monomoraic, incurring a violation of STRESS-TOWeight. It is also monosyllabic, and thereby violates FootBinarity. The initial syllable of candidate (a) is bimoraic and unstressed, violating WEIGHT-TO-STRESS.

In addition to the possibility of stress on an initial closed syllable, there may also be stress on an initial open syllable. Our syllabification strategy should prefer final stress on words with final closed syllables, given the pressure of ALIGNRight and the buffering effect of the word-final onset. Penultimate stress, however, will be preferred 
when the penultimate vowel in the input is bimoraic. Final stress in such words could be achieved only through violation of MAxLinK- $(\mu)[\mathrm{SEG}]$, and since MAxLinK- $(\mu)[\mathrm{SEG}]$ dominates AlignRight, the pressure to move stress rightward abates.

Penultimate CVV stress with a final closed syllable

\begin{tabular}{|c|c|c|c|c|c|}
\hline $\mathrm{ko}_{\mu \mu} \mathrm{ko}_{\mu} \mathrm{s}$ & $\mathrm{SW}$ FB & $\mathrm{MAXL}_{\mu}$ & WS & NF NoCoda & $\mathrm{AR}$ \\
\hline a. $\operatorname{ko}_{\mu}\left(. \mathrm{kó}_{\mu \mu}.\right) \mathrm{s}$ & I & $* !$ & & 1 & * \\
\hline b. $\left(\mathrm{kó}_{\mu \mu}.\right) \mathrm{ko}_{\mu} \cdot \mathrm{s}$ & 1 & & & 1 & $* *$ \\
\hline
\end{tabular}

The optimal candidate in (23) preserves the two morae on the penultimate vowel of the input. It is marked only by having stress two syllables away from the right edge of the word, a relatively low cost property. The best competitor for this candidate is given as candidate (a) above. It improves on the alignment requirement, but at the cost of a faithfulness violation.

If the penultimate vowel were not bimoraic in the input, then the faithfulness constraint MAXLinK- $(\mu)[\mathrm{SEG}]$ would play no role and a candidate like (a) would be optimal. This is precisely the situation to be presented next.

\subsubsection{Final stress on polysyllabic words}

If no consonants in the input are moraic - in contrast with the analysis of eddik in (22) and if no vowel in the input is bimoraic - in contrast with the analysis of kokos in (23) we should see effect of AlignRight favoring stress on the final syllable, rather than the penultimate one. A representative example would be the word tomát, in which the final vowel is lengthened. The choice between satisfying STRESS-TO-WEIGHT through a coda consonant or a long vowel will reveal the preferences of NoCODA.

Final CVV stress with a final closed syllable

\begin{tabular}{|c|c|c|c|c|c|c|c|c|}
\hline \multicolumn{3}{|r|}{$\mathrm{to}_{\mu} \mathrm{ma}_{\mu} \mathrm{t}$} & SW FB & $\mathrm{MAXL}_{\mu}$ & WS & $\mathrm{NF}$ & NoCoda & $\mathrm{AR}$ \\
\hline & a. & 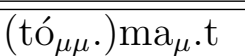 & I & & & & & $* * !$ \\
\hline & & $\operatorname{to}_{\mu}\left(. \mathrm{má}_{\mu} \mathrm{t}_{\mu} \cdot\right) \mathrm{t}$ & $\begin{array}{l}1 \\
1\end{array}$ & & & & $* !$ & $*$ \\
\hline Iff & c. & $\operatorname{to}_{\mu}\left(. \mathrm{má}_{\mu \mu}.\right) \mathrm{t}$ & 1 & & & & 1 & $*$ \\
\hline
\end{tabular}

If the final consonant is moraic in the input, then MAxLinK- $(\mu)[\mathrm{SEG}]$ and NoCodA are in conflict, and the relatively superior $\operatorname{MAxLINK}-(\mu)[\mathrm{SEG}]$ selects the candidate with a short vowel and a word-final geminate.

Stress on a final closed syllable in a disyllabic word 


\begin{tabular}{|c|c|c|c|c|c|c|c|c|}
\hline & & $\operatorname{tra}_{\mu} \mathrm{fi}_{\mu} \mathrm{k}_{\mu}$ & SW FB & $\mathrm{MAXL}_{\mu}$ & WS & $\mathrm{NF}$ & NoCoda & $\mathrm{AR}$ \\
\hline & a. & $\left(\operatorname{trá}_{\mu} \mathrm{f}_{\mu} \cdot\right) \mathrm{fi}_{\mu} \cdot \mathrm{k}$ & I & $* !$ & & & * & $* *$ \\
\hline & & $\left(\operatorname{trá}_{\mu \mu} \cdot\right) \mathrm{fi}_{\mu} \cdot \mathrm{k}$ & I & $* !$ & & & & $* *$ \\
\hline & & $\left(\right.$ trá $\left._{\mu \mu}\right) \mathrm{fi}_{\mu} \mathrm{k}_{\mu} \cdot \mathrm{k}$ & $\begin{array}{l}1 \\
1\end{array}$ & & $* !$ & & & $* *$ \\
\hline & & $\operatorname{tra}_{\mu} \cdot\left(\right.$ fí $\left._{\mu \mu}.\right) \mathrm{k}$ & 1 & $* !$ & & & & * \\
\hline 眐 & e. & $\operatorname{tra}_{\mu} \cdot\left(f^{\prime} \mathrm{i}_{\mu} \mathrm{k}_{\mu}.\right) \mathrm{k}$ & 1 & & & & * & * \\
\hline
\end{tabular}

Any attempt to put the stress on the penultimate syllable, as in candidates (a-c), will lead to a violation of MAXLINK- $(\mu)$ [SEG] if the mora of the final consonant is sacrificed (candidates $\mathrm{a}-\mathrm{b}$ ), or to a violation of WeIGHT-TO-STREss if it is not (candidate $\mathrm{c}$ ). When stress appears on the final syllable, respecting NoCODA also requires a faithfulness violation (candidate d), such that the best strategy will be to preserve the mora on the $[\mathrm{k}]$.

As we have seen in tableaux (22)-(25), a disyllabic word with a final consonant may have stress in one of two positions, either on the penultimate syllable or on the final one. It may be worth emphasizing at this point our view of the task assigned to the phonology. The job of the phonology is to return as optimal the patterns which are possible in the language. In the case of consonant-final words, there are two possible stress patterns, each of which has two possible syllable structures. This would of course mean that a word which might be written edikk could exist, as well as a work which might be written traffik, i.e. words segmentally like eddik and trafikk, but which have stress on the 'other' syllable. And, indeed, these would be possible words of Norwegian, is as clear from the existence of both patterns. The job of the grammar is not to predict that eddik exists as a word in the language while edikk does not; it is rather to predict that both could exist.

\subsubsection{Final stress on monosyllabic words}

At this point, the analysis of the monosyllabic data from (2) should be predictable. They will be analyzed in the same way as words which have final stress and a wordfinal consonant, as we have just seen in $\S 4.2 .2$. The optimal candidate associated with an input in which no consonants are specified as moraic will have a long vowel and a word-final onset, like the final syllable of tomat. The optimal candidate for an input with a final moraic syllable will have a short vowel and a final doubly-linked geminate, like the final syllable of trafikk.

Input with a monomoraic vowel and nonmoraic consonant

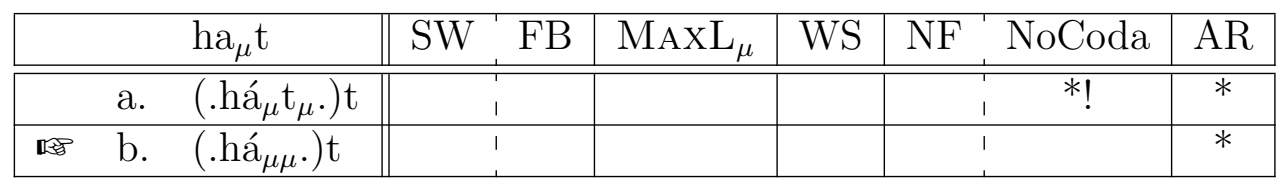


In (26) we see that when faithfulness does not distinguish the candidates, a syllable with a long vowel and no coda is preferred.

If the input has a mora on the final consonant, then candidate (a) will be optimal, given the violation of MAXLINK- $(\mu)[\mathrm{SEG}]$ which is incurred by candidate (b), as in (27).

Input with a monomoraic vowel and moraic consonant

\begin{tabular}{|c|c|c|c|c|c|c|c|}
\hline & $\mathrm{ha}_{\mu} \mathrm{t}_{\mu}$ & SW FB & $\mathrm{MAxL}_{\mu}$ & WS & $\mathrm{NF}$ & NoCoda & AR \\
\hline I & "a. $\left(\right.$. háa $\left._{\mu} \mathrm{t}_{\mu}.\right) \mathrm{t}$ & 1 & & & & $*$ & $*$ \\
\hline & b. $\left(. h a_{\mu \mu}.\right) \mathrm{t}$ & 1 & $* !$ & & & & $*$ \\
\hline
\end{tabular}

The highly ranked markedness constraints will prevent any other structure for a monosyllabic word than the two seen above. The methodological decision to explain surface patterns without restrictions on inputs (the richness of the base) requires that we consider an input with a bimoraic vowel and a moraic consonant. Not surprisingly, this input will map onto an output with a long vowel, as below.

Input with a bimoraic vowel and moraic consonant

\begin{tabular}{|cl||c|c|c|c|c|c|c|}
\hline & ha $_{\mu \mu} \mathrm{t}_{\mu}$ & SW & FB & MAxL $_{\mu}$ & WS & NF & NoCoda & AR \\
\hline \hline a. & $\left(. h a_{\mu} \mathrm{t}_{\mu}.\right) \mathrm{t}$ & & $*$ & & & $* !$ & $*$ \\
\hline b. & $\left(. h \dot{a}_{\mu \mu}.\right) \mathrm{t}$ & & $*$ & & & & $*$ \\
\hline
\end{tabular}

A constraint which explicitly compels double linking for final moraic consonants is unnecessary. The nature of the generator function includes what Prince and Smolensky (1993) call freedom of analysis, which will return candidates such as (a) above. A singly linked final moraic consonant will violate NonFInALITY and therefore be inferior to the doubly linked alternative.

\section{$5 \quad$ Analytical implications}

The analysis developed above has implications for a number of situations which have not yet been considered. In the present section, we review a few of these cases.

\subsection{Intervocalic clusters}

The data considered in our discussion of native disyllabic words was restricted to pairs illustrating the contrast between vowel and consonant length. The examples with short vowels in the stressed syllable all had subsequent geminates. However, intervocalic clusters are also possible, and our grammar makes a prediction about the syllabification of such clusters. Most monomorphemic words with an intervocalic cluster will syllabify 
the first consonant as a coda, even if the cluster could in principle be an onset. As an example, a loan with this shape is liste '(a) list'. As is familiar from the tableaux above, the optimal candidate will have a short vowel in a stressed syllable when the input has a monomoraic penultimate vowel followed by a moraic consonant.

Intervocalic clusters as a coda-onset sequence

\begin{tabular}{|c|c|c|c|c|c|c|c|}
\hline & $\operatorname{li}_{\mu} \mathrm{s}_{\mu}$ te & $\mathrm{SW}, \mathrm{FB}$ & $\mathrm{MAXL}_{\mu}$ & WS & $\mathrm{NF}$ & NoCoda & $\mathrm{AR}$ \\
\hline 畹 & a. $\quad\left(\operatorname{li}_{\mu} \mathrm{s}_{\mu}.\right)$ te & 1 & & & & $*$ & $*$ \\
\hline & b. $\quad\left(\mathbf{l}_{\mu \mu}.\right)$ ste & 1 & $* 1$ & & & & $*$ \\
\hline
\end{tabular}

Candidate (a) is optimal in (29) because the faithfulness constraint MAxLinK- $(\mu)[\mathrm{SEG}]$ distinguishes the candidates before NoCoDA does. The coda consonant in candidate (a) earns a violation of NoCODA, but at that point the competitor in candidate (b) has already been eliminated.

When faithfulness does not distinguish the candidates, then NoCODA can assert its influence. In particular, if there is an input $\mathrm{CVC}_{1} \mathrm{C}_{2} \mathrm{~V}$ and if $\mathrm{C}_{1}$ is not moraic in this input, then the grammar predicts that a $\mathrm{C}_{1} \mathrm{C}_{2}$ onset will be preferred, provided that $\mathrm{C}_{1} \mathrm{C}_{2}$ is a licit onset cluster. This is comparable to the various discussions of CVCV above, when the intervocalic $\mathrm{C}$ is not moraic in the input, cf. (19). We illustrate this situation schematically in (30) below.

Intervocalic clusters as onsets

\begin{tabular}{|c|c|c|c|c|c|c|}
\hline $\mathrm{CV}_{\mu} \mathrm{C}_{1} \mathrm{C}_{2} \mathrm{~V}_{\mu}$ & $\mathrm{SW}, \mathrm{FB}$ & $\mathrm{MAXL}_{\mu}$ & WS & $\mathrm{NF}$ & NoCoda & $\mathrm{AR}$ \\
\hline a. $\left(\mathrm{CV}_{\mu}^{\prime} \mathrm{C}_{\mu 1} \cdot\right) \mathrm{C}_{2} \mathrm{~V}_{\mu}$ & 1 & & & & *! & $*$ \\
\hline b. $\left(\mathrm{CV}_{\mu \mu}.\right) \mathrm{C}_{1} \mathrm{C}_{2} \mathrm{~V}_{\mu}$ & 1 & & & & & $*$ \\
\hline
\end{tabular}

The prediction is clear. The remaining question is whether or not there is an empirical basis for it. There are countless bimorphemic examples of this shape, including the preterite form of the recent loan a lease 'to lease', which is written leaste and pronounced with a long vowel in the first syllable, forming a minimal pair with liste 'to list'. To avoid the complications of polymorphemic words - such as the possibility of outputoutput correspondence - we should look for examples of monomorphemic words having this shape. Our search reveals some examples, most of which are loanwords, although not all of them are so recent, e.g. påske 'Easter'. (Hubro and åkle are not loans but were historical compounds.)

Monomorphemic $C V_{\mu \mu} . C_{1} C_{2} V$ data

påske 'Easter', sebra 'zebra', pueblo, Duplo, hubro 'Great horned owl', åkle 'tapestry' 
Because of the existence of words such as those in (31), we deem the grammar's ability to return such patterns as optimal to be meritorious.

\subsection{Antepenultimate stress}

The strategy we advocate for building the proper syllable and foot structure in Norwegian is sensitive to the prosodic material in the input. Of particular importance is the presence of morae on consonants and of bimoraic vowels. The interaction of these input morae with the faithfulness constraint may determine the location of stress. One implication of this approach is that stress is not restricted to the final or penultimate syllables. In longer loan words, we may find antepenultimate stress. An example of such a word is Amerika, which is borrowed into Norwegian with antepenultimate stress. The grammar returns as optimal such a structure when the antepenultimate vowel is bimoraic in the input.

$$
\text { Optimizing } C \bar{V}_{\mu \mu} . C V . C V
$$

\begin{tabular}{|c|c|c|c|c|c|c|}
\hline & $\mathrm{A}_{\mu} \mathrm{me}_{\mu \mu} \mathrm{ri}_{\mu} \mathrm{ka}_{\mu}$ & SW FB & $\mathrm{MAXL}_{\mu}$ & WS & NF NoCoda & AR \\
\hline & a. $\quad \mathrm{A}_{\mu} \mathrm{me}_{\mu}\left(. \mathrm{ri}_{\mu \mu}.\right) \mathrm{ka}_{\mu}$ & 1 & $* !$ & & I & * \\
\hline & b. $\quad \mathrm{A}_{\mu}\left(. \mathrm{mé}_{\mu} \mathrm{ri}_{\mu}.\right) \mathrm{ka}_{\mu}$ & $\begin{array}{l}1 \\
1\end{array}$ & $* !$ & & $\begin{array}{l}1 \\
1\end{array}$ & $* *$ \\
\hline & c. $\quad \mathrm{A}_{\mu}\left(. \mathrm{mé}_{\mu \mu}.\right) \mathrm{ri}_{\mu} \mathrm{ka}_{\mu}$ & 1 & & & 1 & $* *$ \\
\hline
\end{tabular}

Candidate (c) is optimal in (32) for reasons that are by now familiar. A striking fact about candidate (c) however is that there could be a foot to the right of the one we see there. A foot dominating the two monomoraic syllables will violate STRESS-TOWEIGHT since this constraint prohibits monomoraic stressed syllables. But a bimoraic foot could be constructed over the penultimate syllable. Compare the optimal candidate in (32) with such a candidate, as in (33). (Stress-to-Weight and FootBinarity are removed from this tableau for typographical reasons.)

Clash

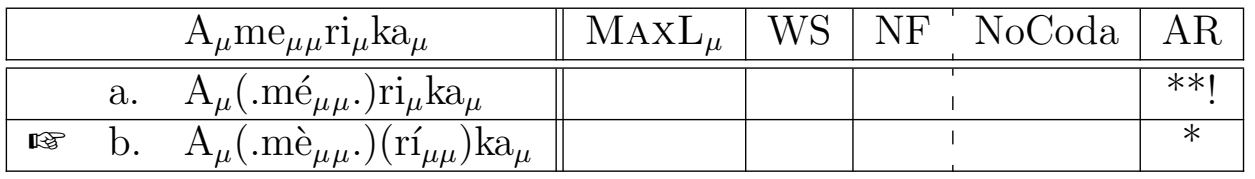

The location of stress with respect to AlignRight is improved with candidate (b) in (33), while faithfulness and the other markedness constraints fail to distinguish the candidates. Yet, this loanword in fact does get antepenultimate stress and not penultimate stress. It seems at this point that another constraint must be introduced to eliminate candidate (b), and we propose that the clashing stresses in this candidate form a basis for eliminating it (Liberman, 1975). The constraint ${ }^{*}$ CLASH prohibits adjacent stressed syllables. 
The tableau in (34) suggests that ${ }^{*}$ CLASH must dominate AlignRight, such that candidate (b) is eliminated before its superior performance on AlignRight becomes relevant.

Optimizing $C \hat{V}_{\mu \mu} . C V . C V$, revisited

\begin{tabular}{|c|c|c|c|c|c|c|}
\hline & $\mathrm{A}_{\mu} \mathrm{me}_{\mu \mu} \mathrm{ri}_{\mu} \mathrm{ka}_{\mu}$ & $\mathrm{MAXL}_{\mu}$ & ${ }^{*} \mathrm{CLASH}$ & WS & NF NoCoda & AR \\
\hline & a. $\mathrm{A}_{\mu}\left(. \mathrm{mé}_{\mu \mu}.\right) \mathrm{ri}_{\mu} \mathrm{ka}_{\mu}$ & & & & । & $* *$ \\
\hline & b. $\quad \mathrm{A}_{\mu}\left(. \mathrm{mè}_{\mu \mu}\right)\left(\mathrm{rí}_{\mu \mu}\right) \mathrm{ka}_{\mu}$ & & $* !$ & & 1 & $*$ \\
\hline & c. $\quad \mathrm{A}_{\mu} \mathrm{me}_{\mu \mu}\left(\mathrm{ri}_{\mu \mu}\right) \mathrm{ka}_{\mu}$ & & & $* !$ & 1 & $*$ \\
\hline & d. $\quad \mathrm{A}_{\mu} \mathrm{me}_{\mu}\left(\mathrm{rí}_{\mu \mu}\right) \mathrm{ka}_{\mu}$ & $* !$ & & & 1 & $*$ \\
\hline
\end{tabular}

If ${ }^{*}$ CLASH were satisfied by preserving the penultimate foot and eliminating the antepenultimate one, Weight-To-Stress and MAxLinK- $(\mu)[\mathrm{SEG}]$ become relevant, as seen in candidates (c) and (d) above.

While we have seen that it is possible to select as optimal a candidate with antepenultimate stress - reflecting borrowings in which the native stress is preserved - it is important to note that antepenultimate stress is not always preserved in these cases. When it is not, stress on the loans in Norwegian surfaces on the penultimate syllable, revealing this as the default location for stress. When an input lacks any bimoraic vowels or moraic consonants, then the grammar will select as optimal candidates in which stress appears on the penult, as we have seen above. This would be the case for Amerika, as well since candidate (d) in (34) would be the winner, were there no faithfulness violation. Examples of words which have antepenultimate stress in their source but penultimate stress for at least some speakers of Norwegian include narkotika and place names such as Veneto, Potamos and Paleochora (O. Lorentz, p.c.).

\subsection{Final clusters}

Our discussion of stress patterns on words with final closed syllables in $\S 4.2$ did not consider words with final clusters. Here again, final or penultimate stress is possible, agurk being an example of the former and boraks an example of the latter. Stress on the final syllable is not surprising. In the case of agurk, the $[\mathrm{r}]$ is a moraic coda, and the $[\mathrm{k}]$ is a final onset. Stress on [gur] will be preferred because it is further to the right than the initial [a].

The challenge lies in treating the words like boraks with penultimate stress. In particular, the problem is to understand why stress on [rak] is not superior to stress on the penult. Following the strategies established above, we assume that penultimate stress on this word should be optimal when the penultimate vowel in the input is bimoraic. This is illustrated (35).

Candidate (a) has to its merit a relatively rightward stress placement and respect for Weight-TO-Stress. These successes, however, come at the expense of a faithfulness violation, and since MAXLINK- $(\mu)[\mathrm{SEG}]$ is relatively highly ranked, candidate 
(a) is excluded from further consideration. Candidate (b) reaffirms the importance of including ${ }^{*} \mathrm{CLASH}$ in the analysis, ruling out stress on adjacent syllables. Candidate (c) offers a structure which respects MAxLinK- $(\mu)[\mathrm{SEG}]$ but also places stress further to the right. The absence of a foot on the penultimate bimoraic syllable leads to a fatal violation of WEIGHT-TO-STRESS.

Candidate $(\mathrm{d})$ keeps stress on the bimoraic penult. However, our view throughout the preceding discussion has been that coda consonants must be moraic. This view is respected in candidate $(\mathrm{d})$, with a moraic $[\mathrm{k}]$ in the final syllable. Since that syllable is unstressed, this also leads to a violation of Weight-TO-Stress. Note that if WeightTO-STRESS is a constraint which can be violated on the surface, then the conditions will be created for the relatively low ranked AlignRight to reassert itself. That is, a competition between candidate (c) and candidate (d) will be won by candidate (c), with its more rightward stress placement, overriding the effects on the bimoraic penultimate vowel in the input.

Candidate (e) fails to respect the view taken throughout that codas must be moraic, and syllabifies the $[\mathrm{k}]$ as a coda in the final syllable without making it moraic. When this move is made, a candidate can respect MAxLinK- $(\mu)[$ SEG] and WeIGHT-TO-STress, and the candidate will therefore be optimal, even though it incurs two violations of AlignRight.

Stress on an initial open syllable in a word with a final cluster

\begin{tabular}{|c|c|c|c|c|c|c|c|}
\hline & $\mathrm{bo}_{\mu \mu} \mathrm{raks}$ & $\mathrm{MAxL}_{\mu}$ & ${ }^{*} \mathrm{CLASH}$ & WS & $\mathrm{NF}$ & NoCoda & AR \\
\hline & a. $\mathrm{bo}_{\mu}\left(\mathrm{rá}_{\mu} \mathrm{k}_{\mu} \cdot\right) \mathrm{s}$ & $* !$ & & & & * & $*$ \\
\hline & b. $\quad\left(\mathrm{bò}_{\mu \mu}\right)\left(\mathrm{rá}_{\mu} \mathrm{k}_{\mu} \cdot\right) \mathrm{s}$ & & $* !$ & & & * & * \\
\hline & c. $\quad$ bo $_{\mu \mu}\left(\right.$. rá $\left._{\mu} \mathrm{k}_{\mu}.\right) \mathrm{s}$ & & & $* !$ & & * & $*$ \\
\hline & d. $\left(\right.$ bó $\left._{\mu \mu} \cdot\right) \mathrm{ra}_{\mu} \mathrm{k}_{\mu} \cdot \mathrm{s}$ & & & $* !$ & & $*$ & $* *$ \\
\hline 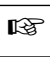 & e. $\quad\left(\right.$ bó $\left._{\mu \mu}.\right) \mathrm{ra}_{\mu} \mathrm{k} . \mathrm{s}$ & & & & & * & $* *$ \\
\hline
\end{tabular}

The question of whether boraks should be represented with a moraic or nonmoraic $[\mathrm{k}]$ is a theoretical question, not an empirical one and we leave the matter ultimately unresolved here, as fodder for future work on both Norwegian and syllable theory more generally. If one determines that the nonmoraic option is desirable, then the constraint compelling moras on codas must be dominated by WEIGHT-TO-STRESS, such that candidate (e) is optimal. This approach would make Norwegian look like Kashmiri, as analyzed in Morén (2000).

If candidate (e) is to be precluded, then the relevant constraint requiring moraic codas (e.g. Weight-BY-Position) must be higher than Weight-TO-Stress, as must MAxLink- $(\mu)[\mathrm{SEG}]$, as noted in (17). Furthermore, it would still be necessary to identify the criterion by which candidate (c) will lose to candidate (d). Here there are proposals in the literature which could be invoked, for example faithfulness to a head in the input, as advocated by Alderete (2001) or McCarthy (2000), which would favor candidate $(\mathrm{d})$ over candidate $(\mathrm{c})$ in $(35)$. 


\section{Conclusion}

Words in contemporary Norwegian can have primary stress on the final syllable, the penultimate syllable or the antepenultimate syllable. The final and antepenultimate options arise historically from borrowings, and this continues with recent borrowings as well. When stress varies in this way, markedness alone will never be a sufficient basis for an analysis of the location of stress. The position of stress is determined in part by faithfulness.

The phonology of Norwegian uncontroversially shows a contrast in consonant length, which may be represented as a contrast between moraic and nonmoraic consonants. In this way, the inclusion of some prosodic information in lexical representations is necessary. The proposal developed here asserts that all variation in stress can be encoded in this way. Nonetheless, there is clearly a default pattern with penultimate stress, which might be dubbed the 'native' pattern.

Moraic specification in the lexicon is not the same as diacritic marking of stress. In the theory of syllable structure adopted here, morae are prosodic stuff essential to complete representations. Furthermore, the weight and length contrasts in Norwegian consonants are characterized as a contrast between nonmoraic and moraic consonants, such that some moraic specification in the lexicon is inevitable. Our approach to stress simply identifies another motivation - stress assignment - for including moraic information in lexical entries.

Our claim here is that the location of stress in loanwords in Norwegian follows from the grammar of the language. This position is taken because of the lack of synchronic motivation for considering them to be part of any other class than the rest of the lexicon. Nonetheless, the grammar of Norwegian has been influenced by the loanwords, presumably developing from a stage in which only penultimate stress was possible, to one in which the full range of variation seen today follows directly. The alternative, of course, is to continue with a grammar returning only penultimate stress except when some explicit diacritic forces stress to be elsewhere. While this may be a suitable strategy for a word or two which maintain a foreign flavor, it is intuitively unappealing for the Norwegian data. Most of these words have no taste of foreignness to the native speaker. Words like allé or armé or meny or nivå or almost any of the words in (3) are everyday words, surely encountered by language learners from the onset of their

exposure to the language. For this reason, it seems that a synchronic grammar of Norwegian should productively account for the data in (3) just as methodically as in accounts for the data in (1) and (2), the history of the words as loans notwithstanding. 


\section{References}

Alderete, J., 2001. Prosodic faithfulness in Cupeño. Natural language and linguistic theory 19, 455-502.

Behne, D., Czigler, P. E., Sullivan, K. P., 1998a. Perceived Swedish vowel quantity: effects of postvocalic consonant duration. Phonum 6, 91-97.

Behne, D., Czigler, P. E., Sullivan, K. P., 1998b. Perceived Swedish vowel quantity: effects of postvocalic voicing. Phonum 6, 83-89.

Blevins, J., 1995. The syllable in phonological theory. In: Goldsmith, J. (Ed.), Handbook of Phonological Theory. Basil Blackwell, Oxford, pp. 206-244.

Broselow, E., 1995. Skeletal positions and moras. In: Goldsmith, J. (Ed.), The Handbook of Phonological Theory. Blackwell, Oxford, pp. 175-205.

Burzio, L., 1995. Principles of English stress. Cambridge University Press, Cambridge.

Curtis, E. K. J., 2003. Geminate weight: Case studies and formal models. Ph.D. thesis, University of Washington.

Davis, S., 2003. The controversy over geminates and syllable weight. In: Féry, C., van de Vijver, R. (Eds.), The Syllable in Optimality Theory. Cambridge University Press, Cambridge, pp. 77-98.

Eliasson, S., 1985. Stress alternations and vowel length: New evidence for an underlying nine-vowel system in Swedish. Nordic journal of linguistics 8, 101-129.

Fretheim, T., 1969. Norwegian stress and quantity reconsidered. Norsk Tidsskrift for Sprogvidenskap 23, 76-96. Reprinted in E. H. Jahr \& O. Lorentz (eds.)1983 Fonologi/Phonology. Oslo: Novus. 315-34.

Harris, J., Gussman, E., 2003. Word-final onsets. Rutgers Optimality Archive 575.

Hayes, B., 1989. Compensatory lengthening in moraic phonology. Linguistic Inquiry 20, 253-306.

Hayes, B., 1995. Metrical stress theory: Principles and case studies. Chicago University Press, Chicago.

Hyman, L., 1985. A theory of phonological weight. Foris, Dorcrecht.

Kager, R., 1995. Consequences of catalexis. In: van der Hulst, H., van de Weijer, J. (Eds.), Leiden in Last: HIL Phonology Papers I. Holland Institute of Generative Linguistics, The Hague, pp. 269-298.

Kaye, J., 1990. 'Coda' licensing. Phonology 7, 301-330.

Kiparsky, P., 1992. Catalexis. Ms., Stanford University.

Kristoffersen, G., 1991. Aspects of Norwegian syllable structure. Ph.D. thesis, University of Troms $\varnothing$.

Kristoffersen, G., 1992. Kvantitet i norsk. Norsk lingvistisk tidsskrift 10, 187-208.

Kristoffersen, G., 1999. Quantity in Norwegian syllable structure. In: Hulst, H. v. d., Ritter, N. (Eds.), The syllable. Facts and views. Mounton de Gruyter, Berlin, pp. 631-650.

Kristoffersen, G., 2000. The phonology of Norwegian. Oxford University Press, Oxford. Kristoffersen, G., 2001. Lengdemotsetningen i nordisk enda en gang. Maal og minne 1, 
65-84.

Kristoffersen, G., 2003. Stress placement in Norwegian. CASTL Kick-off Conference, Troms $\varnothing$.

Landrø, M. I., Wangensteen, B., 1986. Bokmålsordboka: Definisjonsog rettskrivningsordbok. Universitetsforlaget, Oslo. Available online at http://www . dokpro.uio.no/ordboksoek.html.

Liberman, M., 1975. The intonational system of English. Ph.D. thesis, MIT.

Lorentz, O., 1996. Length and correspondence in Scandinavian. Nordlyd 24, 111-128.

McCarthy, J. J., 2000. The prosody of phase in rotuman. Natural language and linguistic theory 18, 147-197.

McCarthy, J. J., Prince, A., 1986. Prosodic morphology. Ms., University of Massachusetts, Amherst and Brandeis University.

McCarthy, J. J., Prince, A., 1993. Prosodic morphology I. Constraint interaction and satisfaction. Manuscript, University of Massachusetts, Amherst and Brandeis University; available at http://roa.rutgers.edu.

McCarthy, J. J., Prince, A. S., 1994. The emergence of the unmarked: Optimality in prosodic morphology. In: Gonzàlez, M. (Ed.), Proceedings of the North East Linguistics Society 24. GLSA, Amherst, Massachusetts, pp. 333-379.

Morén, B., 1999. Distinctiveness, coersion, and sonority: A unified theory of weight. Ph.D. thesis, University of Maryland. Published 2001, Routledge.

Morén, B., 2000. The puzzle of Kashmiri stress: Implications for weight theory. Phonology $17,365-396$.

Prince, A., 1990. Quantitative consequences of rhythmic organization. In: Deaton, K., Noske, M., Ziolkowski, M. (Eds.), CLS 26-II: Papers from the Parasession on the Syllable in Phonetics and Phonology. Chicago Linguistic Society, Chicago.

Prince, A. S., Smolensky, P., 1993. Optimality Theory. Constraint Interaction in Generative Grammar. Tech. Rep. \#2, Rutgers University Center for Cognitive Science. (1993 version available at http://roa.rutgers.edu; slightly revised version published in 2004 by Blackwell Publishers).

Riad, T., 1992. Structures in Germanic prosody. Ph.D. thesis, University of Stockholm. Rice, C., 1992. Binarity and ternarity in metrical theory: Parametric extensions. Ph.D. thesis, University of Texas.

Rice, C., 1999. Norwegian. In: van der Hulst, H. (Ed.), Word prosodic systems in the languages of Europe. Mouton de Gruyter, Berlin.

Rice, C., 2001. Review of The Phonology of Norwegian by Gjert Kristoffersen. Phonology 18, 434-438.

Rice, C., 2003. Norwegian quantity and the richness of the base. Manuscript, University of Troms $\varnothing$, available at http://www.hum.uit.no/a/rice.

Ringen, C. O., Vago, R. M., 2002. Geminates: Heavy or long? Ms., University of Iowa and Queens College and The Graduate Center, City University of New York.

Scheer, T., 2005. CVCV Phonology. Mouton, Berlin.

Selkirk, E., 1982. Syllables. In: van der Hulst, H., Smith, N. (Eds.), The structure of 
phonological representations. Foris, Dordrecht, pp. 337-83.

Selkirk, E., 1990. A two root theory of length. University of Massachusetts Occasional Papers 14, 123-171.

Center for Advanced Study in Theoretical Linguistics (CASTL)

University of Troms $\varnothing$

NO-9037 Troms $\varnothing$, Norway

curt.rice@hum.uit.no

http://castl.uit.no 